\title{
Community acquisition of $\beta$-lactamase producing Enterobacteriaceae in neonatal gut
}

\author{
Charu Kothari ${ }^{1}$, Rajni Gaind ${ }^{1 *}$, Laishram Chandreshwor Singh², Anju Sinha ${ }^{3}$, Vidya Kumari ${ }^{4}$, Sugandha Arya ${ }^{4}$, \\ Harish Chellani ${ }^{4}$, Sunita Saxena ${ }^{2}$ and Monorama Deb ${ }^{1}$
}

\begin{abstract}
Background: Commensal flora constitutes a reservoir of antibiotic resistance. The increasing variety of $\beta$-lactamases and the emergence of Carbapenem resistant Enterobacteriaceae (CRE) in community, raise concerns regarding efficacy of $\beta$-lactams. It is important to know the exact load of antibiotic resistance in the absence of any antibiotic selection pressure including via food and water.

In the present study gut colonization in neonates with no direct antibiotic pressure was used as a model to evaluate $\beta$-lactam resistance in the community.
\end{abstract}

Results: In this prospective study, 75 healthy, vaginally delivered, antibiotic naive, breast fed neonates were studied for gut colonization by Extended spectrum $\beta$-lactamases (ESBL), AmpC $\beta$-lactamases hyperproducing Enterobacteriaceae and CRE on day 0,21 and 60. Total 267 Enterobacteriaceae were isolated and E.coli was the predominant flora. ESBL, AmpC and coproduction was seen in 20.6\%, 19.9\% and 11.2\% isolates respectively. ESBL carriage increased threefold from day 1 to 60 showing predominance of CTX-M group 15 (82.5\%), ampC genes were heterogeneous. Colonization with CRE was rare, only one baby harboured Enterobacter sp positive for kpc-2. The reservoirs for these genes are likely to be mother and the environment.

Conclusions: Data strongly suggests that in absence of any antibiotic pressure there is tremendous load of antibiotic resistance to $\beta$-lactam drugs. Wide spread presence of ESBL and AmpC can drive rapid emergence and dissemination of CRE. This is the first report from India which depicts the smaller picture of true antibiotic pressure present in the Indian community.

Keywords: ESBL, AmpC, Carbapenemases, Neonates, Antibiotic resistance, Enterobacteriaceae, Fecal carriage, Gut colonization

\section{Background}

The rapid dissemination of antibiotic resistance in bacteria constitutes a major public health concern worldwide. Selective pressure mediated by the intensive use of antibiotics (both human and non-human) and several mechanisms for genetic transfer could have contributed to the rapid dispersal of antibiotic resistance in the community [1].

Antibiotics target both pathogenic bacteria as well as normal commensal flora, represented by skin, gut, and upper respiratory tract [2]. Current strategies to monitor the presence of antibiotic resistance in bacteria mainly

\footnotetext{
* Correspondence: rgaind5@hotmail.com

'Department of Microbiology, VMMC and Safdarjung Hospital, New Delhi 110029, India

Full list of author information is available at the end of the article
}

rely upon examining resistance in pathogenic organisms and involve only periodic cross-sectional evaluations of resistance in the commensal flora [3,4]. Resistance amongst the commensal flora is a serious threat because a very highly populated ecosystem like the gut may at later stage be source of extra intestinal infection which may spread to other host or transfer genetic resistance element/s to other members of micro-biota including pathogens [5]. Despite this, there is paucity of data regarding the dynamics of antibiotic resistance in commensals.

$\beta$-lactam antibiotics are the most commonly used antibiotics in community as well as hospitals. They are generally characterized by their favorable safety and tolerability profile as well as their broad spectrum activity [6]. The ever increasing variety of $\beta$-lactamases raises serious concern about our dependence on $\beta$-lactam 
drugs. Rapidly emerging $\beta$-lactamases include diverse ESBL, AmpC $\beta$-lactamases, and carbapenem-hydrolyzing $\beta$-lactamases. ESBL producing Enterobacteriaceae were initially associated with nosocomial infections, however, recent studies indicate significant increase in the community isolates [7]. The risk posed by community circulation of the multidrug resistant bacteria is emphasized by the high concentration of ESBL in the community as well as the hospital onset intra-abdominal infections [8].

The rapid dissemination of ESBL's in community may drive excessive use of carbapenems. The recent report of Carbapenem resistance due to dissemination of NDM-1 $\beta$-lactamase producing bacteria in the environmental samples and key enteric pathogens in New Delhi, India may have serious health implications [9]. Several studies have been conducted to assess the risk factors associated with colonization and infection caused by ESBL producing Enterobacteriaceae, which include antibiotic use, travel, contact with healthcare system and chronic illness $[10,11]$.

Gut colonization in neonates with no direct antibiotic pressure were used as a model to evaluate $\beta$-lactam resistance in the community in absence of selection pressure.

\section{Methods}

\section{Design overview, setting, and participants}

In this prospective study all low birth weight neonates (LBW) $(\geq 1500$ to $<2500 \mathrm{~g})$ born at the Safdarjung Hospital, New Delhi, India (2009-2011) were eligible and enrolled to study 'Effect of Probiotic VSL\#3 on prevention of sepsis during $0-2$ month period'. This is double blind study in which neonates were randomized to receive either VSL\# 3 for 30 days in intervention group or physically similar preparation (Maltdextrin) in control group. The consent was obtained from parents of each neonate prior to enrolment. The stool samples from 75 randomly selected LBW neonates were used to study gut colonization with ESBL, AmpC and carbapenemase producing Enterobacteriaceae. The inclusion criteria were vaginally delivered, healthy and exclusively breast fed LBW neonates. The exclusion criteria were gross congenital malformations, hospitalization, prematurity, predisposing factors for sepsis, antibiotics use by mother during pregnancy and neonates during study period. After discharge from the hospital, trained field workers visited the newborns for probiotic supplementation, collection of stool sample and related complications up to 60 days of life. The study was duly approved by ethical committee of Safdarjung Hospital.

\section{Study of colonization by Enterobacteriaceae}

Stool samples were collected on Day (D) 1, 21 and 60, serially diluted and plated on McConkey agar without antibiotic to study dominant gut flora. D1 sample is the first stool passed after birth (meconium). Different colony types of gram negative bacteria which were judged to differ in morphology (size, shape, consistency and colour) from each sample were enumerated separately and identified using conventional biochemical tests.

\section{Phenotypic assessment and molecular characterization of antimicrobial susceptibility}

All Enterobacteriaceae isolated were screened for ESBL using disk diffusion and Etest methods (AB BIODISK, Solna, Sweden) and plasmid mediated AmpC or hyperproduction using $\mathrm{AmpC}$ disc test [12]. In 27 randomly selected neonates Enterobacteriaceae were characterised for ESBL $\left(b l a_{T E M}, b l a_{S H V}\right.$ (self designed, Table 1), bla $a_{C T X-M}$ (group1, 2, 8, 9 and 25]) [13] and ampC (MOX, CIT, DHA, ACC, EBC, and FOX) [14] genes.

\section{Carbapenemase screening}

All neonates were screened for gut colonization by carbapenem resistant Enterobacteriaceae (CRE) using 2step broth enrichment method incorporating $10 \mu \mathrm{g}$ meropenem disc [15]. Suspected CRE isolates with resistance to any one carbapenem [16] i.e. ertapenem (Minimum inhibitory concentration $(\mathrm{MIC})>0.25 \mu \mathrm{g} / \mathrm{ml}$ ), imipenem and meropenem ( $\mathrm{MIC}>1 \mu \mathrm{g} / \mathrm{ml}$ ) by Etest (bioMérieux, France) were tested for metallo- $\beta$ lactamase (MBL) production using IPM/ethylenediamine tetra-acetic acid (EDTA) Etest and for non-metallo-carbapenemase (NMC), especially KPC, production by the modified Hodge test (MHT) [16]. PCR for VIM, IMP, KPC and $N D M-1$ genes (self designed, Table 1) was performed for confirmation.

\section{Sequence analysis}

All isolates found to carry $E S B L / a m p C$ or carbapenemase gene were further confirmed by sequencing. Sequencing was performed as per manufacturer's guidelines in $3130 \times 1$ genetic analyser (Applied Biosystems, Foster city, California). Further the nucleotide and deduced amino acid sequences were analyzed and compared with sequences available in Gene bank at the National centre of Biotechnology Information (NCBI) web site (http:// www.ncbi.nlm.nih.gov/).

\section{Results}

Gut colonization pattern of Enterobacteriaceae and distribution of ESBL and AmpC $\beta$-lactamases in healthy low birth weight Neonates (1-60 days)

On D1, 65.3\% of babies were colonized with Enterobacteriaceae with no significant increase on D60. The predominant flora was $E$. coli on day 1,21 and 60 followed by Klebsiella pneumoniae (Table 2). 
Table 1 Primers used for detection of TEM, SHV and Carbapenemase genes

\begin{tabular}{|c|c|c|c|}
\hline \multirow[t]{2}{*}{ Primers } & \multirow[t]{2}{*}{$\begin{array}{l}\text { Primer Sequence } \\
\text { (5' to } 3^{\prime} \text { direction) }\end{array}$} & \multirow{2}{*}{$\begin{array}{l}\text { Annealing } \\
\text { Temperature } \\
\left({ }^{\circ} \mathrm{C}\right)\end{array}$} & \multirow{2}{*}{$\begin{array}{l}\text { Amplicon } \\
\text { size } \\
\text { (bp) }\end{array}$} \\
\hline & & & \\
\hline \multirow[t]{2}{*}{ TEM } & $\begin{array}{l}\text { FP- ATG AGT ATT CAA CAT } \\
\text { TTC CG }\end{array}$ & 50 & 858 \\
\hline & $\begin{array}{l}\text { RP- CCA ATG CTT AAT CAG } \\
\text { TGA GG }\end{array}$ & & \\
\hline \multirow[t]{2}{*}{ SHV } & $\begin{array}{l}\text { FP- ATG CGT TAT ATT CGC } \\
\text { CTG TG }\end{array}$ & 58 & 862 \\
\hline & $\begin{array}{l}\text { RP- AGC GTT GCC AGT GCT } \\
\text { CGA TC }\end{array}$ & & \\
\hline \multirow[t]{2}{*}{ KPC-1 } & $\begin{array}{l}\text { FP- AGC CGT TAC AGC CTC } \\
\text { TGG AG }\end{array}$ & 55 & 1351 \\
\hline & $\begin{array}{l}\text { RP- GAT GGG ATT GCG TCA } \\
\text { GTT CAG }\end{array}$ & & \\
\hline \multirow[t]{2}{*}{ KPC-2 } & $\begin{array}{l}\text { FP- CAC TGT ATC GCC GTC } \\
\text { TAG TTC }\end{array}$ & 55 & 812 \\
\hline & $\begin{array}{l}\text { RP- TGT GCT TGT CAT CCT } \\
\text { TGT TAG }\end{array}$ & & \\
\hline \multirow[t]{2}{*}{ NDM-1 } & FP- CGACGATTGGCCAGCAAATG & 58 & 551 \\
\hline & RP- ACTTGGCCTTGCTGTCCTTG & & \\
\hline \multirow[t]{2}{*}{ IMP } & FP- TTGAAAAGCTTGATGAAGGCG & 58 & 616 \\
\hline & RP- ACCGCCTGCTCTAATGTAAG & & \\
\hline VIM & FP- TTGACCGCGTCTATCATGGC & 58 & 762 \\
\hline
\end{tabular}

Overall ESBL and AmpC production was $20.6 \%$ and $19.9 \%$ respectively. The total isolates positive for either AmpC and or ESBL were 29.2\% (78/267). The predominant phenotypes were co-producers (30/267, 11.23\%), followed by only ESBL $(25 / 267,9.4 \%)$ and AmpC (23/
267, 8.6\%) isolates. Both no. of babies colonized with at least one ESBL producing isolate and ESBL rate amongst Enterobacteriaceae increased three fold ( $\mathrm{p}$ value 0.005 and 0.001 respectively) from day 1 to day 60 , irrespective of associated AmpC production (Table 2).

\section{Characteristics of ESBL and AmpC $\beta$ - lactamases in Enterobacteriaceae isolates from 27 randomly selected neonates}

The three stool samples from 27 neonates generated 88 gram negative bacilli which included E.coli $(\mathrm{N}=74)$, Klebsiella pneumoniae $(\mathrm{N}=11)$, Citrobacter freundii $(\mathrm{N}=2)$ and Enterobacter aerogenes $(\mathrm{N}=1) . C T X-M-15$ is predominant ESBL, TEM-136, TEM-149, SHV-28 and $C T X-M-8$ was seen in single isolates. In contrast, the $a m p C$ was diverse and included $D H A(\mathrm{~N}=5), C M Y-2$ $(\mathrm{N}=3), C M Y-1(\mathrm{~N}=2), M O X(\mathrm{~N}=2)$ and FOX $(\mathrm{N}=1)$ (Table 3).

\section{Colonization by carbapenem resistance}

Enterobacteriaceae in the neonates

Total 225 stool samples from 75 enrolled babies were screened for CRE 2-step broth enrichment method incorporating $10 \mu \mathrm{g}$ meropenem disc. Gram negative colonies were isolated from 22 stool samples, which yielded 29 Enterobacteriaceae isolates that were presumed to be CRE. Phenotypic test for MBL was negative, MIC of 28 suspected CRE ranged from $0.012-0.5 \mu \mathrm{g} / \mathrm{ml}$, $0.016-0.125 \mu \mathrm{g} / \mathrm{ml}$ and $0.094-0.38 \mu \mathrm{g} / \mathrm{ml}$ for ertapenem, meropenem and imipenem respectively. However, one isolate of Enterobacter aerogenes. was positive for MHT having the $\mathrm{MIC}$ of $>32 \mu \mathrm{g} / \mathrm{ml}$ for ertapenem, meropenem

Table 2 Distribution of Enterobacteriaceae and associated ESBL and AmpC $\beta$-lactamases in Neonates

\begin{tabular}{|c|c|c|c|c|}
\hline & Total & $\begin{array}{c}\text { Day } 1 \\
(\mathrm{~N}=75) \\
\text { No. }(\%)\end{array}$ & $\begin{array}{l}\text { Day } 21 \\
(\mathrm{~N}=75) \\
\text { No. }(\%)\end{array}$ & $\begin{array}{l}\text { Day } 60 \\
(\mathrm{~N}=75) \\
\text { No. }(\%)\end{array}$ \\
\hline Babies colonized with a least one species & & $49(65.3)$ & $48(64)$ & $53(70.6)$ \\
\hline No of babies colonized with at least one ESBL producing isolate & & $7 / 49(14.3)$ & $13 / 48(27.1)$ & $22 / 53(41.5)^{*}$ \\
\hline Total Enterobacteriaceae strains \# & 267 & 79 & 88 & 100 \\
\hline E.coli & 219 & $69(87.3)$ & $67(76.1)$ & $83(83)$ \\
\hline Klebsiella pneumoniae & 27 & $3(3.8)$ & $13(14.8)$ & $11(11)$ \\
\hline Enterobacter $s p$ & 14 & $2(2.5)$ & $7(8)$ & $5(5)$ \\
\hline Citrobacter sp & 5 & $4(5.1)$ & 0 & $1(1)$ \\
\hline Salmonella. Typhi & 2 & $1(1.3)$ & $1(1.1)$ & 0 \\
\hline Total ESBL & $55(20.6)$ & $7(8.9)$ & $17(19.3)$ & $31(31)^{* *}$ \\
\hline Total AmpC $(\mathrm{N}=39)$ & $53(19.9)$ & $16(20.3)$ & $12(13.6)$ & $25(25)^{* * *}$ \\
\hline Co-Production of ESBL and AmpC & $30(11.2)$ & $5(6.3)$ & $9(10.2)$ & $16(16)^{* * * *}$ \\
\hline
\end{tabular}

Note: Data represents Enterobacteriaceae isolates from gut of 75 healthy Low birth weight (LBW) neonates on Day 1, 21, 60 of birth.

All Figures in parentheses represent percentages.

\# Some babies had more than one morphologically and biochemically distinct isolates.

*p value $0.005{ }^{* *}$ p value $0.001 * *$ p value $0.2 * * * p$ value 0.05 when compared to Day 1 . 
Table 3 Molecular Characterization of ESBL \& AmpC $\beta$-lactamases in Enterobacteriaceae isolated $(\mathbf{N}=88)$ from 27 randomly selected neonates

\begin{tabular}{|c|c|c|c|c|c|c|c|c|c|c|c|c|}
\hline \multirow[t]{2}{*}{ Phenotype } & \multirow[t]{2}{*}{ No. strains } & \multicolumn{4}{|c|}{ ESBL } & \multicolumn{7}{|c|}{ AMPc } \\
\hline & & bla-TEM & ESBL TEM & SHV & CTX-M & $\overline{D H A}$ & CMY-1 & CMY-2 & LAT & MOX & BIL & FOX \\
\hline$E+A+$ & 7 & 7 & $2^{*}$ & $1 * *$ & $4 \#$ & 2 & & 3 & & 2 & & 1 \\
\hline$E+A-$ & 10 & 10 & & & 10 & & & & & & & \\
\hline $\mathrm{E}-\mathrm{A}+$ & 5 & 5 & & & & $3 \# \#$ & 2 & & & & & \\
\hline E-A- & 66 & \multicolumn{11}{|c|}{$\begin{array}{l}\text { PCR not performed for strains with cefotaxime, ceftazimime zone diameter } \geq 28 \text { and } \geq 23 \text { respectively and phenotypic test } \\
\text { negative for ESBL and AmpC } 16\end{array}$} \\
\hline
\end{tabular}

Note: Sequencing results *Tem 136, Tem 149; ${ }^{*}$ SHV28. E = ESBL, A = AmpC, - = Negative, + = Positive.

\# ESBL and AMPC genes were mainly isolated in E.coli except one Klebsiella pneumoniae having both CTX-M as well as MOX gene.

\#\# One Citrobacter showed the presence of DHA gene.

and imipenem. Presence of $k p c-2$ gene was confirmed by PCR using gene specific primers.

\section{Discussion}

In the present report we have investigated the $\beta$-lactam resistance pattern amongst Enterobacteriaceae in gut flora of neonates (1-60 days) by enrolling babies using various selection criteria so as to avoid any possible source of antibiotic selection pressure. Acquisition of resistance through food and water was also ruled out as neonates were exclusively breast fed. Compliance was ensured through household follow up by trained field workers upto D60 of life.

The present study shows that majority of the babies were colonized by D1. With the acquisition of mother's flora the babies are equally likely to get the antibiotic resistance strains. Our data revealed that overall there was nearly $87 \%$ (232/267) resistance to the ampicillin by D60 in Enterobacteriaceae. The overall rate of ESBL was $20.6 \%$ which may be just a glimpse of bigger picture as in the present study only dominant population was studied. Selective media were not used for screening ESBL gut carriage which would reflect the true representation of ESBL carriage in the community. The low isolation of ESBL producers on D1 may be due to the short duration of exposure to the maternal flora during delivery (Table 2). Various factors could have contributed to the increase in the resistance by day 60 . After delivery, exposure related to mothers environment, oral and skin flora provide the major sources of bacteria which may transfer to the neonates by several ways including suckling, kissing and caressing. In addition, breast milk is also a source of bacteria, which contains up to $10^{9} \mathrm{mi}-$ crobes/L in healthy mothers [17]. Other sources may be household contact with siblings, pets [18], as well as horizontal transfer of gene within the commensal flora [1]. In our study acquisition of resistance via supplementary food has been ruled out as babies were completely breast fed. Several studies have shown the prevalence of antibiotic resistance in absence of direct use of antibiotic. Presence of tetracycline resistance bacteria in breastfed infants [19] and commensal ESBL producers in pre-school healthy children [20] suggest contamination in the family environment rather than direct exposure to antibiotic. The limitation of our study is that we have not studied the environmental flora and compared it with that of neonatal gut flora.

Besides ESBL, AmpC producing Enterobacteriaceae were also isolated. AmpC producing isolates were approximately $20 \%$ and co-production with ESBL was seen in $11.2 \%$ throughout the study period (Table 2). AmpC $\beta$-lactamases producers are of major concern as they are resistant to $\beta$-lactam and $\beta$-lactam inhibitor combination as well as cefoxitin which further narrows down the treatment options. As carbapenems are drug of choice for $\mathrm{ESBL}$ and or AmpC producing bacteria, coexistence of these enzymes can pose a threat to the community acquired pathogens as MIC of such strains are 10 fold higher for various carbapenems [21].

The $a m p C$ gene showed diverse profile, in contrast $C T X-M-15$ was predominant ESBL gene in gut flora. Previous studies from India have also shown $C T X-M-15$ as predominant ESBL from clinical isolate [22]. Approximately, $50 \%$ of neonates admitted to neonatal unit in our hospital with early onset sepsis had ESBL producing Enterobacteriaceae [23] which is strongly supported by early colonization with ESBL producing Enterobacteriaceae in the neonates in the present study.

Recent report of isolation of CRE (NDM-1) from environmental samples [9] and community acquired infections [24] indicate that CRE producing NDM-1 enzyme may be widely distributed in India. However, there is paucity of data regarding fecal carriage of CRE in the community in absence of antibiotic pressure. Different studies have used different culture based techniques like MacConkey agar plates supplemented with $1 \mu \mathrm{g} / \mathrm{ml}$ imipenem, Chrom Agar KPC, Mac Conkey Agar with imipenem, meropenem and ertapenem disc $(10 \mu \mathrm{g})$ and two step selective broth enrichment method using $10 \mu \mathrm{g}$ carbapenem disc to evaluate gut colonization with CRE with good performance [15]. Most of these techniques are validated for KPC detection in organisms with MIC 
range $0.5->32 \mu \mathrm{g} / \mathrm{ml}$ for various carbapenems [15]. Nordmann et.al. screened $27 N D M-1$ positive isolates and reported that the MIC of these isolates vary from $0.5->32 \mu \mathrm{g} / \mathrm{ml}, 1.5-231>32 \mu \mathrm{g} / \mathrm{ml}$ and $1.5->32 \mu \mathrm{g} / \mathrm{ml}$ for ertapenem, meropenem and imipenem respectively. However, only one isolate i.e. P Providencia rettgeri A showed MIC of $0.5 \mu \mathrm{g} / \mathrm{ml}$ for ertapenem [25]. In present study with 2 step broth enrichment method using meropenem disc only one strain of Enterobacter sp was positive by MHT and PCR confirmed presence of $k p c-2$ gene. MIC of other 28 suspected CRE isolates were $\leq$ $0.5 \mu \mathrm{g} / \mathrm{ml}$ for all carbapenems. Two isolates were positive for ESBL and AmpC, having MIC of $0.5 \mu \mathrm{g} / \mathrm{ml}$ for ertapenem but were negative for carbapenem genes.

In the present study widespread resistance to Ampicillin and 3rd generation cephalosporin (3GC) was observed but carbapenem resistance was rare. This can be explained by indiscriminate use of $3 \mathrm{GC}$ in human and animals due to availability of oral formulations and over the counter unrestricted access. Ampicillin and 3GC are used as an empirical therapy in India for the management of neonatal sepsis and other heath related complications like UTI, meningitis, bacterial sepsis $(6,1)$. The high prevalence of resistance to these drugs as indicated in our study raises the question regarding the efficacy of these antibiotics as an empirical therapy.

Carbapenems on the other hand are used sparingly as they are available as parentral formulation for which a patient have to visit the health care facility and in addition there is no reports of their use in animals from India. It is noteworthy that the presence of $k p c-2$ gene in antibiotic naive neonates may be an alarming finding as carbapenem resistance genes are on plasmids and have a potential for rapid dissemination in future. Commensal flora can colonize the human gut without causing any symptoms, but most of the infections are endogenous and come from patient's own gut flora [26].

The present study estimate of $\beta$-lactam resistance may be biased due to following reasons. Babies were supplemented with probiotics which have beneficial effect on gut by producing organic acids, bacteriocins, peptides and in turn decreasing $\mathrm{pH}$ of gut leading to inhibition of colonization of Enterobacteriaceae [27]. In addition, only the subdominant population was screened for ESBL carriage resulting in an under estimate of ESBL in the community. However, this data could not be an overestimate as there are no reports of presence of $E S B L$ genes in probiotic bacteria or transfer of antibiotic resistant genes from gram positive (Probiotic) bacteria to gram negative bacteria.

\section{Conclusions}

Our data strongly suggest there is a tremendous load of ESBL and/or AmpC in the community in absence of any direct selection pressure indicating that these genes are widely distributed in the environment. This may result in significant increase in carbapenem use in community resulting in development of carbapenem resistance which may be due to porin loss with ESBL or de-novo spread of true carbapenemases. In conclusion there is a need to make efforts to determine the resistance load present in the different environmental pools (human, animal, and plants).

\section{Competing interests}

The authors declare that they have no competing interests.

\section{Authors' contributions}

CK carried out all phenotypic work, DNA extraction, PCR, sequencing, and drafted the manuscript. RG conceived of the study and participated in its design, and edited the manuscript. LCS had done the analysis of the sequencing data. AS have designed the study. VK monitored the mother and the neonates for clinical outcomes and have trained the field workers. SA supervised the monitoring of the clinical outcomes. $\mathrm{HC}$ designed the clinical study and edited the manuscript. SS and MD had done the final editing and approved the final manuscript. All authors have read and approved the final manuscript.

\section{Acknowledgements}

This work was supported by Indian Council of Medical Research, Govt. of India. Grant No. 5/7/156/2006-RHN.

\section{Author details}

${ }^{1}$ Department of Microbiology, VMMC and Safdarjung Hospital, New Delhi 110029, India. ${ }^{2}$ National Institute of Pathology, Indian Council of Medical Research, New Delhi 110029, India. ${ }^{3}$ Indian Council of Medical Research, New Delhi 110029, India. ${ }^{4}$ Department of Paediatrics, VMMC and Safdarjung Hospital, New Delhi 110029, India.

Received: 14 January 2013 Accepted: 6 June 2013 Published: 17 June 2013

\section{References}

1. Hawkey PM, Jones AM: The changing epidemiology of resistance. J Antimicrob Chemother 2009, 64(Supp I):i3-i10.

2. Andremont A: Commensal flora may play key role in spreading antibiotic resistance. ASM News 2003, 69:601-607.

3. Caprioli A, Busani L, Martel JL, Helmuth R: Monitoring of antibiotic resistance in bacteria of animal origin: epidemiological and microbiological methodologies. Int J Antimicrob Agents 2000, 14:295-301.

4. Fantin B, Duval X, Massias L, Alavoine L, Chau F, Retout S, Andremont A, Mentré F: Ciprofloxacin dosage and emergence of resistance in human commensal bacteria. J Infect Dis 2009, 200:390-398.

5. Macpherson AJ, Harris NL: Interactions between commensal intestinal bacteria and the immune system. Nat Rev Immunol 2004, 4:478-485.

6. Lode HM: Rational antibiotic therapy and the position of ampicillin/ sulbactam. Int J Antimicrob Agents 2008, 32:10-28.

7. Cantón R, Novais A, Valverde A, Machado E, Peixe L, Baquero F, Coque TM: Prevalence and spread of extended-spectrum beta-lactamase-producing Enterobacteriaceae in Europe. Clin Microbiol Infect 2008, 14:144-153.

8. Hawser SP, Badal RE, Bouchillon SK, Hoban DJ, and the SMART India Working Group: Antibiotic susceptibility of intra-abdominal infection isolates from India hospitals during 2008. J Med Microbiol 2010, 59:1050-1054

9. Walsh TR, Weeks J, Livermore DM, Toleman MA: Dissemination of NDM-1 positive bacteria in the New Delhi environment and its implications for human health: an environmental point prevalence study. Lancet Infect Dis 2011, 11:355-362.

10. Guillet M, Bille E, Lecuyer H, Taieb F, Masse V, Lanternier F, Lage-Ryke N, Talbi A, Degand N, Lortholary O, Nassif X, Zahar JR: Epidemiology of patients harboring extended-spectrum beta-lactamase-producing enterobacteriaceae (ESBLE), on admission. Med Mal Infect 2010, 40:632-636 
11. Wiener J, Quinn JP, Bradford PA, Goering RV, Nathan C, Bush K, Weinstein RA: Multiple antibiotic-resistant Klebsiella and Escherichia coli in nursing homes. JAMA 1999, 281:517-523.

12. Mohanty S, Gaind R, Ranjan R, Deb M: Use of the cefepime-clavulanate ESBL Etest for detection of extended-spectrum beta-lactamases in AmpC co-producing bacteria. J Infect Dev Ctries 2010, 4:24-29.

13. Woodford N, Fagan EJ, Ellington MJ: Multiplex PCR for rapid detection of genes encoding CTX-M extended-spectrum (beta)-lactamases. J Antimicrob Chemother 2006, 57:154-155.

14. Perez-Perez FJ, Hanson ND: Detection of plasmid-mediated AmpC $\beta$-lactamase genes in clinical isolates by using multiplex PCR. J Clin Microbiol 2002, 40:2153-2162.

15. Landman D, Salvani JK, Bratu S, Quale J: Evaluation of techniques for detection of carbapenem-resistant Klebsiella pneumoniae in stool surveillance cultures. J Clin Microbiol 2005, 43:5639-5641.

16. Clinical and Laboratory Standard Institute: Performance of standards for antimicrobial susceptibility testing; Twenty-first Information supplement M100S21. Wayne, PA: Clinical and Laboratory Standard Institute; 2011.

17. Schanler RJ, Fraley JK, Lau C, Hurst NM, Horvath L, Rossmann SN: Breastmilk cultures and infection in extremely premature infants. J Perinatol 2011 , 31:335-338.

18. Nowrouzian F, Hesselmar B, Saalman R, Strannegard IL, Aberg N, Wold AE, Adlerberth I: Escherichia coli in infants' intestinal microflora: colonization rate, strain turnover and virulence gene carriage. Pediatr Res 2003, 54:8-14.

19. Gueimonde M, Salminen S, Isolauri E: Presence of specific antibiotic (tet) resistance genes in infant faecal microbiota. FEMS Immunol Med Microbiol 2006, 48:21-25.

20. Pallecchi L, Bartoloni A, Fiorelli C, Mantella A, Di Maggio T, Gamboa H, Gotuzzo E, Kronvall G, Paradisi F, Rossolini GM: Rapid Dissemination and Diversity of CTX-M Extended-Spectrum $\beta$-Lactamase Genes in Commensal Escherichia coli Isolates from Healthy Children from LowResource Settings in Latin America. Antimicrob Agents Chemother 2007, 51:2720-2725.

21. Mohanty S, Gaind R, Ranjan R, Deb M: Prevalence and phenotypic characterization of carbapenem resistance in Enterobacteriaceae bloodstream isolates in a tertiary care hospital In India. Int J Antimicrob Agents 2011, 37:273-275.

22. Walsh TR, Toleman MA, Jones RN: Comment on: Occurrence, prevalence and genetic environment of CTX-M $\beta$-lactamases in Enterobacteriaceae from Indian hospitals. J Antimicrob Chemother 2007, 59:799-800.

23. Sehgal R, Gaind R, Chellani H, Agarwal P: Extended-spectrum beta lactamaseproducing gram-negative bacteria: clinical profile and outcome in a neonatal intensive care unit. Ann Trop Paediatr 2007, 27:45-54.

24. Kumarasamy KK, Toleman MA, Walsh TR, Bagaria J, Butt F, Balakrishnan R, Chaudhary U, Doumith M, Giske CG, Irfan S, Krishnan P, Kumar AV, Maharjan S, Mushtaq S, Noorie T, Paterson DL, Pearson A, Perry C, Pike R, Rao B, Ray U, Sarma JB, Sharma M, Sheridan E, Thirunarayan MA, Turton J, Upadhyay S, Warner M, Welfare W, Livermore DM, et al: Emergence of a new antibiotic resistance mechanism in India, Pakistan, and the UK: a molecular, biological, and epidemiological study. Lancet Infect Dis 2010, 10:597-602.

25. Nordmann P, Poirel L, Carrër A, Toleman MA, Walsh TR: How to detect NDM-1 producers. J Clin Microbiol 2011, 49:718-721.

26. Bloomfield SF, Cookson B, Falkiner F, Griffith C, Cleary V: Methicillinresistant Staphylococcus aureus, Clostridium difficile, and extendedspectrum beta-lactamase-producing Escherichia coli in the community: assessing the problem and controlling the spread. Am I Infect Control 2007, 35:86-88

27. Gillor O, Etzion A, Riley MA: The dual role of bacteriocins as anti- and probiotics. Appl Microbiol Biotechnol 2008, 81:591-606.

doi:10.1186/1471-2180-13-136

Cite this article as: Kothari et al:: Community acquisition of $\beta$-lactamase producing Enterobacteriaceae in neonatal gut. BMC Microbiology 2013 13:136.

\section{Submit your next manuscript to BioMed Central and take full advantage of:}

- Convenient online submission

- Thorough peer review

- No space constraints or color figure charges

- Immediate publication on acceptance

- Inclusion in PubMed, CAS, Scopus and Google Scholar

- Research which is freely available for redistribution 